\title{
Description of Andesperuviel/a gen.n. (Acari, Oribatei, Hammeriellidae) from the Peruvian Andes
}

\author{
Adilson D. Paschoal ${ }^{1}$
}

\begin{abstract}
A new genus Andesperuviella (Acari, Oribatei, Hammeriellidae) is described. The type species, Pedrocortesia dentata Hammer, 1961 is redescribed in detail. The genus, up to the present, is monotypic and restricted to the Peruvian Andes.
\end{abstract}

Andesperuviella gen $\mathbf{n}$.

Type species: Pedrocortesia dentata Hammer, 1961

Diagnosis - Andesperuviella is close to Hammeriella Paschoal, 1989 from which it differs mainly by the following characteristics: legs intensively reticulate; adults without exuviae; apo c absent; le dorso-lateral; bothridium dark, away from notogastral margin; ss elongate, slightly claviform; $r 2$ lateral, on tubercle, well at notogastral margin; notogaster ovate; apo II, apo sj with anterior extensions; genital and anal apertures contiguous not touching one another; anal aperture pyriform; apo pad, apo pag present; gl not on genitalia proximal margin; ag postero-lateral to genitalia; adl posterior to anal plate; femoral crests present; tarsi (it), (tc) not on apophyses, short, thick; fi Tb II close to d; $\mathbf{v}$ ' Ge II, IV present; pl'Ts IV present.

Description - Body and legs of clarified specimens covered by a thin layer of cerotegument presenting microtubercles; notogastral, prodorsal, ventral cuticle foveate or reticulate; legs intensively reticulate forming cavities on all segments. Exuviae absent on adult body. apo le absent; apo ro with a transversal nervure; apo ex with mammillate protuberances facing equal formation from apo ro; apo $\mathrm{c}$ absent. Prodorsum with no deep transversal furrow on tooth $\mathbf{p}$ region. le dorso-lateral, on tubercle, away from ro; ro lateral; ex short, below and ahead of bothridium; in short, lanceolate; bothridium dark, dorso-lateral, away from notogastral margin; ss elongate, slightly claviform, covered by short black spines. psl further apart from its homologous seta than hl; integument invaginated between psl setae; ps2, ps3 close together and to ps1, at a lower level

1 ESALQ-USP, Caixa postal, 9, 13.400 Piracicaba - SP. 
than $\mathrm{ps} 1$, both posterior to $\mathbf{r} 2$; h1 terminal, very close to its homologous seta, without crossing each other at the sagital plane; r2 (1p) lateral, well at notogastral margin; close to ip, set on tubercle; $\mathbf{r} 3(1 \mathrm{~m})$ absent. Lyrifissures median to large; ip well developed, oblique. Notogaster flat, ovate; large size mites around $800 \mu$. Epimeral apodemata with strong apodematic bonds; apo II with a transversal bar provided with two parallel extensions turned to mentotectum base; apo ij with a transversal bar pointed to apo II, presenting two mammillate protuberances laterally on epimeral furrow; apo IV as a hat over genitalia; epimeral chaetotaxy $3: 1: 3: 3$. Genital and anal apertures contiguous, close but not touching one another; anal aperture pyriform; genitalia proximal margin at the level of coxae IV; genital and anal plates foveate; apo ad, apo pad, apo ag, apo pag present. Genitoanal chaetotaxy $7-1-3-3$; genital setae on a sole longitudinal row, close to inner margin, almost equidistant except for $\mathrm{gl}$; $\mathrm{gl}$ on a depression of inner margin of genitalia, at a short distance from distal margin; anal setae also on a sole longitudinal row; ag postero-lateral to genital plate, very close to it; adl posterior to the anal plate. Tb I apophysis short; tarsi pedicels extremely short, bearing three equally strong claws, the medial one a little longer than the laterals; Ts I famulus enclosed; femora with chitinous, prominent crests; tibiae with no parallel crests, but with greatly sclerotized dorsal areas; tarsi (it), (tc) not on apophyses, short, thick, covered by long spines all around; (u), (a), s well developed, with long spines ventrally only; fi Tb II close to d; v' Ge II, III, IV present; pl' Ts IV present; Fe III with d, l' proximal and $\mathbf{v}$ ' at the same level as $\mathbf{d}$; other chaetotaxic features as described for the family (PASCHOAL, 1988). Leg chaetotaxy:Ts. 19(2) - 17(2) $16-15 ;$ Tb. $4(2)-5(1)-4(1)-4(1) ;$ Ge. $4(1)-4(1)-3(1)-3 ; \mathrm{Fe} .5-$ $5-3-2 ; \operatorname{Tr} .1-1-2-1$.

Discussion - The generic name Andesperuviella refers to the collecting area, i.e., the Peruvian Andes.

Andesperuviella dentata (Hammer, 1961) comb. n.

Pedrodortesia dentata Hammer, 1961: 36, fig. 28.

Types - Female lectotype no. 684, collected by Marie Hammer from humid moss in Machu Picchu, Peruvian Andes, with no collecting date; four paralectotypes, same as above. Depository: Zoologisk Museum, Copenhagen, Denmark.

Diagnosis - A. dentata is close to Hammeriella grandis (Hammer) (PASCHOAL 1989) from which it differs mainly by the following characteristics: notogastral foveae small, well aside; prodorsum smooth; genital and anal plates with minute foveae; genitoanal region without cuticular thickenings; epimeral foveae absent; no exuviae on adult body; apo ro with just a transversal nervure; apo c absent; apo in not Y-shaped; le dorso-lateral; bothridium opening lateral; ss not so distally expanded; notogaster ovate; $r 2$ lateral, well at notogastral margin; hl no crossing its homologous seta; apo II with two parallel extensions; 
apo sj with mammillate protuberances; genital and anal plates not touching one another; anal aperture pyriform; apo pad, apo pag present; gl away from genitalia distal margin; anal setae spiny; ag postero-lateral; adl posterior to anal plate; femoral crests present; with well sclerotized areas on tibiae; (it), (tc) not on apophysis; $\mathbf{d}$ Ge I at the end of the segment; v' Ge III present; v'Fe III at the same level of d; pl'Ts IV present.

Description - Integument - Cuticle granular, covered by a thin layer of cerotegument presenting microtubercles, uniformely spread on notogaster. Prodorsal and leg microtubercles larger. Ventral microtubercles rare. Notogastral cuticle foveate, with small circular foveae set apart one from the other; lateral foveae inexistent. Prodorsum smooth on general appearance, with almost imperceptible foveae. Laterally on metapodosome and ventrally on anal region foveae are large, well apart, joint together by a well developed reticulum. Genital and anal plates with minute obscure foveae. Epimeral region without foveae. Leg cuticle intensively reticulate, with large cavities on all segments. Exuviae absent on adult body. Prodorsum - Apo le absent; apo ro a transversal nervure; a loop linked to the homologous part is formed laterally; apo c absent; apo ex a short bar originated on bothridium, joint to another bar emerging from acetabulum II, ending by a mammillate protuberance facing equal formation of apo ro; apo in a weakly sclerotized arch linking in to apo ex, apo bo; apo bo a well sclerotized bar bearing in, linking bothridia. Prodorsum without a furrow on pedotectal tooth p region. le anterior, away from ro, set on tubercle, dorsolateral, smooth, bent to the sagital plane, tip touching its homologous seta; ro lateral, smooth, also bent to the sagital plane; ex short, smooth, below and ahead of bothridium; in short, lanceolate, turned up and to the rear, set on strong tubercle. Bothridium dorso-lateral, the opening turned to the side, being black, at a short distance from notogastral margin; distance between bothridia $142.8 \mu \quad(F)$; ss elongate, slightly clavate, covered by short, black spines, emerging straight and then bending in obtuse angle to the rear; ss lenght $107.1 \mu(\mathrm{F})$. Prodorsum lenght $192.5 \mu(\mathrm{F})$. Notogaster - Dorsum flat; notogaster ovate. With notogastral tectum between lines bng and lambda. With five pairs of lyrifissures; ia almost parallel to the margin; im perpendicular on oblique to the margin; ip well developed, larger than im, oblique to the margin; ih, ips as long as im. Latero-abdominal gland opening posterior to im, not so close to it. With five pairs of notogastral setae; r2 (1p) lateral, well at notogastral margin, close to ip, set on tubercle, being short, smooth, bent downward; hl terminal, smooth, quite close to its homologous seta, not crossing it at the sagital plane, set on tubercle; psl a little further apart from its homologous seta than hl, set on tubercle; integument between psl shallowly invaginate; ps2, ps3 on small apophyses, close together and to ps1, both posterior to $\mathbf{r} 2$. Notogaster lenght $618.7 \mu(\mathrm{F})$; width $481.3 \mu(\mathrm{F})$; lenght/width 1,28 (F). Epimeral region - a, $\mathbf{m}$ short; labio-genal apodeme poorly sclerotized; $\mathbf{h}$ on small apophysis; mentotectum broad. Apo I complete, well developed close to acetabulum I, linked to the homologous part by a transversal bar; apo II incomplete, also developed also developed at coxal region, linked by a poorly sclerotized transversal bar to the homologous part, presenting two parallel extensions pointed to mentotectum base; apo si incomplete, well sclerotized 
at coxal region, also with a transversal bar linking the homologous parts, from which a perpendicular extension emerges directely to apo II, bifurcating then to delimit epimere II furrow; two mamillate protuberances, directed one to the other, occur laterally on epimeral furrow; apo III a short incomplete bar, not linked to the homologous part by a transversal bar; epimeral furrow III delimited by a parallel bar to apo III; apo IV incomplete, short; a transversal bar resembling a hat occurs over genitalia, delimiting ep. III, IV. Epimeral chaetotaxy 3: 1: 3: 3; epimeral setae short, on small apophyses, Genitoanal region - Genital and anal apertures contiguous, close together but not touching one another; genital aperture almost square; anal aperture pyriform. Genitalia proximal margin at the level of coxae IV. Genitalia length $172 \mu(\mathrm{F})$; width $137.5 \mu(\mathrm{F})$; anal aperture lenght $192.5 \mu(\mathrm{F})$; width $151.3 \mu(\mathrm{F})$. Genitalia inner margin weakly sclerotized; anal plate inner margin and anal and genital outer margin well sclerotized. Apo ag, apo ad, apo pag, apo pad present; apo pag oblique to genitalia forming a loop close to the lateral border; apo pad a long oblique bar close to the lateral border of body. Genitalia plate ornated with very small reticulum forming foveae; anal plate provided with larger but fewer foveae than the genital plate, also obscure. Genitoanal chaetotaxy $7-1-$ 3 - 3; genital setae short, slender, curved, on a sole longitudinal row, almost equidistant except for $\mathbf{g l}$; gl on a depression of genitalia inner margin at a short distance from distal margin of the plate; anal setae also on a sole longitudinal row, being short, straight, spiny, set on depressions of the inner margin; ag seta postero-lateral to genitalia, very close to it, between the plate and apo ag, as long as the epimeral setae; ad setae on small apophyses; ad 3 at a height equivalent to the proximal third of the plate, being the furthest; ad 2 at a height equivalent to the posterior third of the plate; adl posterior to the plate. Lateral characters - Tectopedia absent; with a pedotectal tooth $\mathbf{p}$, much alike a true pedotectum when seen from above, being not auriculiform however. Lateral carenae present. Acetabula I, II integument and cotyloid forming a blunt structure. Legs $-\mathrm{Ts}-\mathrm{Tb}, \mathrm{Tb}-\mathrm{Ge}, \mathrm{Ge}-\mathrm{Fe}$ articulations on proximal sockets, i.e., sockets on tarsi, tibiae, genua proximal ends. Femoral and trochanteral tracheae present, with large stigmata on the segment bases. Distal apophyses on Ts I, II. Famuli enclosed on Ts I, II. Trochanter and Fe - Tr articulations of all legs outside acetabula. Femora orientation after the articulation with trochantera almost straight. Tarsi pedicels extremely short; with three strong claws, the medial one slightly larger than the laterals. Leg segments normally developed. Femora of all legs with prominent ventral chitinous crests on distal portion, not reaching genua; tibiae with no parallel crests and with greatly sclerotized dorsal areas. Proral setae normally developed except on Ts I; (it), (tc) not on apophyses, short, thick, covered with spines all over the surface; (u), (a), s smaller than the previous one, with long spines ventrally only; other setae longer, not so strong, not on apophyses. Ts. I - ft" dorsal, very close to omega; ft' dorso-lateral, close to ft"; pv" anterior to pv', away from it; pl', pl" almost at the same level; v'A anterior to v'A; (p) eupathidia; omega 1 paraxial, slender and longer than omega 2; omega 2 anti-axial solenidia on dorsal, antiaxial apophysis; famulus enclosed; Ts. length $127.5 \mu(\mathrm{F})$. Tb. I $-\mathbf{v}^{\prime}, \mathbf{v}^{\prime}$ at the same transversal plane; tibial apophysis short, dorsal, 
antiaxial, covering proximal tarsus end only; fi2 short, antiaxial, behind fil; Tb. length $101 \mu(\mathbf{F})$. Ge. I - 1', 1', v' on almost the same transversal plane at proximal half; d dorsal, short, very close to sigma; sigma slender, setaceous; Ge. lenght $56.3 \mu$ (F). Fe. I - d well developed; l', l' close to distal end, almost at the same transversal plane; two v", one median one proximal; Fe. lenght $187.5 \mu$ (F). Tr. I - one sole seta, long; Tr. length $56.3 \mu$ (F). Ts. II - ft" anterior to $\mathrm{ft}^{\prime}$ ', not too close to it; pl' present, at the same transversal plane with pl "; pl' anterior to pv", close to it; omega 1 close to omega 2, paraxial, a little larger than it; Ts. length $108.7 \mu$ (F). Tb. II - d dorsal, at distal margin, close to fi; l' anterior to 1"; 1" at half of the segment; (v) slightly anterior to 1'; fi antiaxial, long, on small apophysis at distal tibia; Tb. length $97.5 \mu(\mathrm{F})$. Ge. II - d dorsal, short, at proximal end; l',l" at the same transversal plane; $v$ 'present; sigma short, antiaxial, close to d; Ge. length $56 \mu$ (F). Fe. II - d well developed, I', I" at the same transversal level, distal; 2 v", one proximal, one distal; Fe. length $150 \mu(\mathrm{F})$. Tr. II - one sole seta, long, ventral; Tr. length $56.2 \mu$ (F). Ts. III - ft' present, posterior, away from ft"; pl" absent; pv' anterior to pv"; solenidia absent, Ts. length $135 \mu$ (F). Tb. III - d antiaxial, close to distal end; v', v" almost at the same transversal plane; l' close to (v); fi short, antiaxial, close to d; Tb. length $116.3 \mu$ (F). Ge. III - d antiaxial, at distal end, close to sigma; l' almost at the same heigth as d; v' present; Ge. length $56 \mu(\mathrm{F})$. Fe. III - d well developed; 1' at proximal end; $\mathbf{v}^{\prime}$ at the same direction as d; Fe. length $131.3 \mu$ (F). Tr. III with l', v'; Tr. length $108.7 \mu(\mathrm{F})$. Ts. IV - ft' absent, (it) present; pl' absent; pl" present; pv' anterior to pv"; solenidia absent; Ts. length $135 \mu(\mathrm{F}), \mathrm{Tb}$. IV - as in Tb III; Tb, length $127.5 \mu(\mathrm{F})$. Ge. IV - as in Ge III; solenidium absent; Ge, length $56 \mu(\mathrm{F})$. Fe IV - d well developed; v' almost at the level of d; Fe. length $135 \mu(\mathrm{F})$. Tr. IV - one sole seta, ventral; Tr. length $150 \mu(\mathrm{F})$. Leg chaetotaxy - Ts.: $19(2)-17(2)-16-15 ;$ Tb .: $4(2)-5(1)-$ $4(1)-4(1)$; Ge.: $4(1)-4(1)-3(1)-3 ;$ Fe.: $5-5-3-2$; Tr.: $1-1-2-$ 1.

Geographical distribution and habitat - Machu Pichu, Peruvian Andes, in humid moss grow on the soil.

Discussion - In describing A. dentata, Hammer (1961) did not designate the holotype among the five adults used to describe it. Consequently they are all syntypes. In 1979, Dr. H. Enghoff, Zoologisk Museum, Copenhagen, sent to me, on loan, a slide labeled $P$. dentata by Hammer. This specimen, used to redescribed the species and to characterize the new genus, is now designated lectotype. All other four specimens are, then, paralectotypes.

\section{REFERENCES}

HAMMER, M. 1961. Investigations on the oribatid fauna of the Andes Mountains. II. Peru. Biol. Skr.Dan. Vid.Selsk. 13 (1): 1 - 157.

PASCHOAL, A. D. 1989. Description of a new genus - Hammeriella gen. n. - from South America and a new family - Hammeriellidae fam. n. (Acari, Oribatei). Revta bras. Zool., 6(1): 17-24. 